\title{
Beyond the Legal Environment: How Stigma Influences Invisible Identity Groups in the Workplace
}

\author{
Joy E. Beatty ${ }^{1,3}$ and Susan L. Kirby ${ }^{2}$
}

Diversity research assumes that social interaction is influenced by a social categorization that arises from visible and readily detectable differences. How does this process work when the differences are not readily detectable? We explore the legal protections that shape the employment environment for people with invisible identities and how invisibility influences the common social dimensions of stigma these individuals experience. These social dimensions are resistant to change and therefore change occurs slowly: stigma cannot simply be legislated away. On the basis of our comparisons of social identity groups with invisible characteristics we discuss four dimensions that are especially relevant for understanding the social dynamics of invisible diversities.

KEY WORDS: gay and lesbian identity; stigma; invisible diversity; legal protections.

Like all diversity groups, a common theme of research in the work experiences of gay and lesbian people is that discrimination in employment is pervasive. Studies have found anywhere from 25 to $66 \%$ of respondents have experienced discrimination including job denial and loss, diminished mobility and limited career choice, termination, ostracism, and even violence (Croteau, 1996; Levine, 1979; Levine \& Leonard, 1984; Taylor, 2002). Perceived workplace discrimination has been associated with more negative work attitudes and fewer promotions (Ragins \& Cornwall, 2001b). These negative outcomes are often the result of fear, stereotyping and misunderstanding.

However, the discrimination gay and lesbian employees face is unusual because it rests upon a generally invisible difference. From both a research and practical perspective, the invisibility of sexual orientation makes this diversity category unique among some of the more common and traditional differences such as gender, race, and age. In the traditional view of workplace diversity, visibility of the difference has been a prerequisite to experiencing the negative effects of diversity on social integration, communication, and group conflict. These categories of difference are laden with meanings triggered by their visibility, meanings which are created and reinforced in social interaction.

\footnotetext{
${ }^{1}$ Management Studies, University of Michigan-Dearborn, Dearborn, Michigan.

${ }^{2}$ Department of Management, Texas State University, San Marcos, Texas.

${ }^{3}$ To whom correspondence should be addressed at Management Studies, University of Michigan-Dearborn, 19000 Hubbard Drive FCS B-29, Dearborn, Michigan 48126; e-mail: jebeatty@umd.umich.edu.
} 
The dynamics of invisible differences are more complex. Social interactions involving differences such as religious beliefs, illness and disability status, or sexual orientation are also socially meaningful differences, but they may not be recognized in every interaction. Visibility, therefore, is a central factor in the management of and reaction to a stigmatized social identity (Crocker et al., 1998; Jones et al., 1984). Goffman identified the challenges involved with managing an invisible stigmatized identity when he wrote: "The issue is not of managing tension generated during social contacts, but rather that of managing information about his failing. To display or not to display; to tell or not to tell; to let on or not to let on; to lie or not to lie; and in each case, to whom, how, when, and where" (Goffman, 1974, p. 42).

Invisibility creates a dilemma for employees seeking the benefits of legal protection against discrimination in the workplace because to receive the benefits they must first disclose their situation. Yet the act of disclosing their difference is potentially career limiting because in doing so they create the grounds for possible stigma and discrimination. In this way, both positive and negative career outcomes hinge upon disclosure. The effects of invisibility and the dilemma of disclosure influence normal social interaction and therefore have implications for the individual as well as group processes in organizations.

This paper explores the contours of the visible/invisible issue by discussing how legal protections shape the employment environment for people with invisible diversities and how invisibility influences the common dimensions of stigma these individuals experience. We draw comparisons among the stigma faced by people with physical differences such mental and chronic illness and invisible disabilities, nontraditional religious beliefs, and gay and lesbian identities. Although we acknowledge that perception of a group's social status varies with context, stigma is common for these groups. This paper contributes to the literature by discussing hidden identities and exploring the unique choice to disclose that people face. In doing so we highlight issues that may be overlooked by scholars studying visible differences. Further, exploring how stigma operates with invisible differences can deepen our understanding of how it operates with visible differences.

The first section discusses the legal protections available in the United States through the Americans with Disabilities Act of 1990 and the Civil Rights Act of 1964 (Title VII). We also explore the limited protection available to gays and lesbians in US workplaces under the First and Fourteenth Amendments and a host of state and local laws. Following that we turn to a discussion of social identity and stigma theories and with respect to invisible identities. We offer four dimensions of stigma, which are especially salient to invisible identities, along with illustrative comparisons.

\section{THE LEGAL ENVIRONMENT AND INVISIBLE IDENTITIES}

Legal protection is important in assuring workplace fairness and opportunity; however, not all groups with hidden identities are protected from discrimination in the same way or to the same extent. Those with mental and physical illnesses have the greatest formal legal protection in the workplace (Schuchman, 1998). The Americans with Disabilities Act of 1990 (ADA) provides protection for people with physical or mental impairment that substantially limits "major life activity." Under the ADA, employers must be made aware of the physical and/or mental limitation before they are required to provide 
"reasonable accommodation" for "qualified individuals" (U.S. Equal Employment Opportunity Commission, 2005a). These accommodations must not impose an "undue hardship" on the operation of the business and it is generally the responsibility of the employee to inform the employer that an accommodation is needed (Repa, 2005; U.S. Equal Employment Opportunity Commission, 2005a).

There are some practical difficulties in implementing the requirements of the ADA. Employers must maintain the safety of the workplace while making reasonable accommodations with respect to employees who pose a direct threat to others, such as employees with violent mental illnesses or contagious illness (Sheffield, 2005). There are also difficulties determining what constitutes a condition covered by the ADA. For example, the US Supreme Court has concluded that a person is not impaired if the condition can be controlled by corrective measures (Repa, 2005; Sheffield, 2005). There is also an imbalance of power with employers having a significant amount of control over the determination of what constitutes the essential functions of a job. Often employers are resistant to implementing accommodations because they perceive that they will be costly and that changing the way work is done could interfere with productivity (Stone \& Colella, 1996). Lastly, employees are reluctant to use the ADA because it moves accommodation discussions into a more formal legal, adversarial mode (Beatty, 2004). Obstacles can be overcome by correctly identifying people with disabilities, exploring a wide range of potential accommodations, effectively implementing reasonable accommodations, and documenting the entire process (Sheffield, 2005).

Title VII of the Civil Rights Act of 1964 also provides federal protection from religiousbased workplace discrimination with coverage extending from those with "sincerely held" beliefs to nonbelievers (Kramer, 1999). Employers may not treat employees or applicants more or less favorably because of their religious beliefs, practices, or lack of belief and employers must reasonably accommodate employees' sincerely held religious beliefs. However, there is a great deal of confusion surrounding the rights and responsibilities of employees and employers in this area of law. There is variability in the courts as to what constitutes a religious belief versus a political belief, and the law is purposely vague (Kramer, 1999; Page, 2005). Another difficulty comes from the individual, ad hoc nature of the application of the law, a necessity due to the variety of situations that arise due to wide variation in religious practices (Schuchman, 1998). In addition to difficulties defining what constitutes protected beliefs, employers must balance the rights of employees to hold and practice their beliefs against the rights of other employees to be free from religious harassment (Rudin \& Harshman, 2004; U.S. Equal Employment Opportunity Commission, 2005b).

Unlike the groups mentioned above, there is no federal nondiscrimination law protecting gay and lesbian employees. The Employment Nondiscrimination Act (ENDA), introduced in 1994 and designed to cover employment discrimination, has been blocked repeatedly in Congress (Cahill, 2005). Lacking comprehensive federal protection, sexual orientation discrimination cases have been tried using basic freedom of speech and equal protection rights provided by the First and Fourteenth Amendments of the US Constitution (cf., Romer v. Evans, 517 U.S. 620, 1996). Invasion of privacy has also been argued as a basis for sexual orientation discrimination cases. These cases involve charging employers with exerting undue control over the private, nonwork lives of employees (Repa, 2005). Although there is no federal employment law protecting gays and lesbians, as of 200516 
states and 173 counties, cities and governmental organizations have laws banning discrimination based on sexual orientation (Herrschaft, 2004). Still, 53\% of the US population lives in a city or jurisdiction where one can be fired from one's job or denied housing because of sexual orientation bias (Cahill, 2005). A lack of comprehensive federal antidiscrimination legislation has left this group vulnerable to discriminatory practices.

Legal protections are not without limitations. In addition to complexities mentioned above, legislation may evoke negative reactions among coworkers if it is perceived as coercive or implemented as preferential treatment (Stone \& Colella, 1996). Offering accommodation can lead to resentment and perceptions of inequity among coworkers. Colella (2001) has found that when disabilities are invisible, self-caused, and socially undesirable, coworkers are less likely to view accommodation as justified. Additionally, stigma is potentially introduced with the legal requirements of disclosure. Because of stigma and other negative social perceptions and stereotypes, disclosure is risky for those with hidden identities. Legislation can often do very little to change affective reactions and relationships between people in the workplace. Further, being part of a legally protected class challenges any possibility of equality; despite its goal of protecting groups, the law creates and reinforces the foundation for stigmatization by categorizing groups, drawing attention to differences (Gordon \& Rosenblum, 2001).

Antidiscrimination laws are important as substantive tools to address wrongs and also as symbols of cultural values about the importance of tolerance and diversity. However laws must reside in the social and cultural environment as well. These environments are more resistant to change, and therefore change occurs slowly: stigma cannot simply be legislated away. Thus in the next section we address the social psychological aspects of stigma and how they apply to invisible social identities.

\section{INVISIBLE SOCIAL IDENTITIES}

Diversity research assumes that social interaction is influenced by a social categorization that arises from visible and readily detectable differences. Based on initial perceptions, people categorize others based on their perceived social identity, categorizing people they perceive as similar to themselves into an in-group and others into out-groups (Tajfel \& Turner, 1985). Membership in a relatively rare group increases group salience and identification (McGuire, 1984). In-group members conform to group norms and discriminate against out-groups, and this identification process is reinforced with ongoing interactions. People attend to social categories because they are assumed to reveal information about the target person. Initial reactions to people are formed based upon visible surface-level differences which are usually overt, biological, and considered to be immutable (Harrison et al., 1998). The resulting initial interpretations are based on well-learned social interactions and often group stereotypes.

How does this process work when the differences are not readily detectable? The visible cue that serves as a triggering mechanism for social categorization no longer operates the same way (Clair et al., 2005). People with invisible stigmatizing differences may choose not to reveal their difference, or they may select the conditions under which they disclose. Thus, the focus shifts to information management as people attend to this decision about how much to reveal. 
Information management strategies require constant attention, which may cause people to become obsessively preoccupied with thoughts of their stigma (Smart \& Wegner, 2000). People with potential stigma must anticipate others' production of intrusive or offensive behavior that occurs when others make false assumptions about the person's identity (Goffman, 1963), and decide how to address it. If they decide to conceal their difference, this requires them to carefully separate the personal and work domains of their lives, creating passing strategies to mask their difference. This leads to fragmentation of the self and feelings of isolation common among many invisible social identities (Beatty \& Kirby, 2004; Frable et al., 1998). Expected duration of relationships plays a role in information management because it is difficult to conceal a stigmatizing mark in longer-term relationships (Jones et al., 1984).

Invisible stigmatized social identities represent an identity threat for individuals at work, operating both socially and psychologically. If a person discloses their stigma, coworkers may avoid them or question their competency at work, damaging relationships and reputations. Establishing credibility and legitimacy under these conditions is difficult. This can preclude developmental job assignments, leading to diminished career opportunities.

The issue of information management is common across a range of invisible identity categories, including sexual orientation (Herek, 1996; Woods, 1994; Woods \& Harbeck, 1991), religion (Blummer, 2005; Dawkins, 2003; Delbecq, 2002; Weithoff, 2003), chronic illness (Beatty, 2004; Charmaz, 1991), mental illness (Corrigan, 2004; Wahl, 1999), and disability (Matthews \& Harrington, 2000). The dimension is operationalized by measures of disclosure to assess whether an employee is "out" at work, meaning that they have communicated this identity to others. Disclosure is not a binary construct, and those with hidden identities exhibit a wide range of disclosure behavior regarding their identity from fully closeted to fully "out" which varies across time and context. Disclosure behaviors fall upon a continuum because people vary in their preferences for disclosure. Stage models of identity development (such as Cass, 1984; Charmaz, 1987) suggest that disclosure of stigmatized identities increase as people come to accept their new identity, further indicating that disclosure is a continuum. It is this range of behaviors that requires information management and constant monitoring. Information management in the workplace is influenced by fear of rejection and negative job outcomes (Ragins \& Cornwall, 2001a), and the competing desire to represent oneself authentically (Moorhead, 1999). Some researchers suggest that concealing one's stigmatized identity leads to a bifurcated self and associated decreased self-esteem, stress, and feelings of being disconnected (Frable et al., 1998; Moorhead, 1999; Woods, 1994; Woods \& Harbeck, 1991). They have found that higher levels of disclosure are associated with positive work attitudes such as affective commitment, job satisfaction, and belief in the support of top management (Croteau, 1996; Day \& Schoenrade, 1997; Driscoll et al., 1996).

\section{DIMENSIONS OF STIGMA AND INVISIBLE DIFFERENCES}

Stigma research offers a useful framework for understanding the dynamics of invisible differences. Stigma is defined as a negative discrepancy between the actual or inferred attributes of an individual versus the expectations for typical individuals in that 
context, such that the individual is regarded as deviant (Goffman, 1963). Our dimensions of invisible differences are adapted from the six dimensions of stigma offered by Jones et al. (1984), which are concealability, course, disruptiveness, aesthetic qualities, origin, and peril. In this paper we elevate the concealability dimension to an overarching category because we believe that all other related social processes hinge on this dimension. The centrality of this dimension is supported by a long history of stigma research. Jones et al. (1984) report that in the eleven empirically grounded discussions of stigma they reviewed to form their dimensions, concealability was almost always included. Concealability also preempts or moderates other dimensions of stigma, such as aesthetic qualities and disruptiveness. The aesthetic distinctions of attractive and unattractive are irrelevant for invisible stigma. Similarly, disruption of social interaction relies partially on the stigma being visible. Although this concealability dimension is presented here as a discrete binary distinction of visible or invisible, this oversimplifies a distinction that is more properly a continuous variable. We maintain the binary distinction here for the purposes of clarity of analysis.

On the basis of our comparisons of social identity groups with invisible characteristics we discuss four dimensions that are especially relevant for understanding the social dynamics of invisible diversities. These dimensions focus on the content and nature of the stigma and how others respond to it. They may also apply to visible differences and are therefore not necessarily unique to invisible differences. The four dimensions we address are the person's responsibility for the stigma, the course of the stigma over time, its moral threat, and its effects on performance.

\section{Responsibility}

In social interaction other people assess blame based on the person's perceived responsibility in acquiring the stigma. If the mark refers to a stigma the person cannot control and is seen as innate and immutable, then the person is seen as a victim and is ascribed less culpability for their situation. Parsons (1951) referred to this as imputed cause and suggested that personal responsibility determines social reactions. Similarly, Falk (2001) refers to this as existential stigma. Visible stigma such as race and gender are seen as existential stigma, beyond the individual's control. Some types of disability and illness can be existential, for example when they are due to congenital conditions or are acquired through an externally caused situation (i.e., a trauma accident).

In contrast, achieved stigma refers to stigma based on people's behaviors, which ostensibly they should be able to control. People with achieved stigma experience higher levels of stigmatization because they are seen as morally responsible for their stigma. These stigma are seen as character flaws reflecting the individual's lack of self-restraint and control, and therefore these people are seen as undeserving of sympathy and acceptance. Examples of this are when smokers develop lung cancer, alcoholics develop liver disease, and gays develop HIV/AIDS. Falk also identifies criminals and prostitutes as having achieved stigma. Laboratory studies to assess the impact of responsibility on social response show that people will punish those they see as responsible for their stigma. In three studies using confederates representing themselves as either responsible or not responsible for their stigma, subjects evaluated the confederate more highly when they were not responsible for their stigma (using mental illness, Farina et al., 1966; using body odor, Levine \& McBurney, 1977; 
using obesity, Vann, 1976). The studies using mental illness and obesity included asking the subjects to administer electric shocks to the confederate, and the shocks were longer when the confederate was seen as responsible for the stigma. Similarly, diseases defined as onset-controllable evoked more blame, anger, and reduced prosocial response than did those diseases defined as onset-uncontrollable (Weiner et al., 1988).

Stigma can be arrayed along a responsibility continuum from existential to achieved, but some stigma cannot be easily classified. Homosexuality is an example of a status that cannot be easily classified on this dimension because of controversies about the cause of an individual's homosexuality. Prior to the mid-1970s, homosexuality was classified by the American Psychiatric Association and American Psychological Association as a mental pathology. In the 1970s the prevailing psychological view shifted from this illness model of homosexuality to the view that it is a natural variant of erotic attractions and relationships (Garnets \& Kimmel, 1991). However, because people discover their sexual orientation relatively late in the process of identity development, it was considered an achieved trait as opposed to an in-born, ascribed one. The belief that homosexuality is a matter of choice is the foundation of the long history of persecution of gays (Falk, 2001).

In the present era some researchers have put forth a medical model of biological essentialism that argues that homosexuality is biologically or genetically endowed. Shifting the responsibility away from individual behaviors to biology shifts the stigma from achieved to existential stigma; theoretically this should lessen the stigma because being homosexual is not something people can control. The disadvantage of biological essentialism is that it characterizes stigma as a biological deficiency of the individual, maintaining its status as "less than" normal and conferring social deficiency (Liachowitz, 1988). Under this view, deviance is located internally in the act or person rather than externally in the social reaction (Gordon \& Rosenblum, 2001). By emphasizing the medical model as the cause of stigmatizing differences, attention is diverted from the critical role of social structures in the production of stigma. The medical model is also common in disability studies, where it focuses on the individual's physical deficiencies as the cause of disability instead of society's incapacity to respond to social variation (Pfeffer, 2001).

\section{Course}

A second dimension that is relevant for invisible differences is the trajectory over time, which Jones et al. (1984) refer to as course of the mark. Some differences are permanent in nature and are considered immutable; others are permeable and change over time (Bell et al., 2004). Members may leave identity groups when defining features are lost, for example when mental or physical illness is cured or religious beliefs are questioned. Variability can also be embedded in the course of the stigmatizing condition itself.

Permanent differences are considered to be more stigmatizing. Religious affiliations and beliefs tend to differ along socioeconomic, racial and geographic lines and are handed down from parents to children early in life, which implies a certain immutability (Dawkins, 2003; Miller, 1996). This immutability could account for the difficulties and misunderstandings seen between people with widely different beliefs (Dawkins, 2003; Miller, 1996; Stark \& Bainbridge, 1987). Research with mental patients supports the notion that permanent differences are considered more stigmatizing. Relatives of mental patients had more 
favorable attitudes about the person when they believed the condition was alterable and could be expected to improve or go away over time (Freeman, 1961; Schwartz, 1957). Similarly, "stigma offset" occurs when the positive hope for future recovery lessens the stigma an individual faces (Weiner et al., 1988).

When there is a possibility that the course can change over time and that it is responsive to the individual's efforts, there is an expectation that the person will act responsibly to overcome or recover from the stigmatizing condition, for example seeing the wisdom of following a set of religious practices or seeking medical help. This is one of the obligations of Parson's (1951) sick role, that patients must take action to try to get better and not malinger.

As Jones et al. (1984) note, beliefs about expected future course are perhaps more important than actual course of the stigma. After all, people cannot always know the pattern a socially degrading condition will follow over time. In a current interaction, people make assessments about the course and permanence of the stigma that shape their behaviors. Those that are perceived as permanent are more permanently stigmatized.

Some diversity groups are permeable due to difficulties in defining them. For example, there are different definitions of disability such that a person may be disabled under one definition and able-bodied under another. In another example, how do we define those with no religious beliefs? West (2004) suggests the term "rationalists" because atheism is not a definition of a belief system but rather a description of lack of belief that depends on belief as the defining feature. Gay and lesbian identities are also hard to define, with definitions relying on gay behaviors and/or identities. As noted above, gay identity often develops later in life, and sexual identity can be in a state of flux during this time until the person reaches the point of officially "changing" their sexual identity. This flux is described in the many stages included in stage models of homosexual identity formation; for example, Cass's (1979) model includes six stages. Similarly, the view that homosexuality is a psychiatric disorder which can be cured rests upon the assumption that this identity is highly permeable and that the perceived boundary between gay and straight is simply a matter of choice. From the perspective of stigma theory this view contains an irony in that people who believe homosexuality is deeply stigmatizing seem also to believe that this identity is easily changed; yet less permanent conditions should be less stigmatizing. However, the overriding factor of responsibility and that homosexuality is an active choice trumps this and creates achieved stigma, and therefore deep stigma remains.

An interesting comparison regarding definitions can be made with racial segregation laws from an earlier era. The Jim Crow laws of the American South used the "one drop rule" to define anyone with a hint of black ancestry as black. Although in practice the drop of blood was hard to identify, on the surface these laws had a clear standard. They were based upon and intended to enforce the belief that racial categories were absolutely immutable (Smedley, 1999). Similarly, although present day laws make attempts at clear definitions, terms such as "deeply held religious beliefs" and "disabilities that cause limitations in major life activities" are as difficult to implement as the "just one drop" standard. Like race, these identities are not immutable and resist clear binary definitions. Indeed one of the issues of diversity research is the tendency to assume discrete categories in race, sexual preference, and disability status; substantial oversimplification is required to create groups (Link \& Phelan, 2001). Further, formal definitions can change over time, as has the definition of mental illness put forth by the American Psychiatric Association. 
Course is relevant for the invisible differences because the course of a stigma can change the level of visibility over time. As the condition or identity becomes more manifest the person's hidden identity may be revealed, essentially "outing" the person's hidden identity to others. For instance, some illnesses and disabilities have symptoms that change over time with degenerative symptoms or periods of increased activity. The symptoms of mental illness can vary in level of severity at different ages in response to developmental changes.

Note that even when a stigmatizing difference disappears, some residual stigma may remain with the individual as a permanent identity blemish. For example, ex-mental patients and ex-convicts are stigmatized for their past membership as mental patients and convicts. Bobys and Laner (1979) found that ex-homosexuals were stigmatized in the same way as homosexuals. Once a variable stigmatizing condition is known, then people are primed to look for remissions and relapses of "deviant" behavior.

\section{Moral Threat}

The moral threat dimension of stigma emphasizes the fact that stigma is a relational phenomenon; attributes are not themselves stigmatizing, so much as they are defined as such by group members. Long ago Goffman (1963) pointed out that stigma should be represented in a language of relationships, not attributes. The cultural conflict model of stigma presumes that the source of stigma is the difference in attitudes that form observers' views of the afflicted (Schulte, 2002). Stigma then is a matter of the social and political attitudes of observers, specifically how much the observers align themselves with opposing political or cultural groups and the dominant cultural sentiments. Further, what is stigmatizing within one's culture is learned through socialization with one's in-group members (Stangor \& Crandall, 2000).

Certain marks are highly stigmatized because they are a symbolic threat to the moral order of society or the onlooker's sense of self. Encountering a marked person makes a person's vulnerability salient and can lead to defensive reactions. Invisible identities are threatening because, unlike the more absolute categories of race and gender, it is possible for an onlooker to adopt (voluntarily or not) the stigmatized identity. An able-bodied person could develop an illness, a person may adopt a religious identity, and a heterosexual person could become gay.

Illness and disability are seen as a moral failure which clashes with business values such as constant activity, speed, ability to keep a schedule, and expectation of good health (Ware, 1999). They also clash with larger cultural images of the 'good citizen' because they interfere with one's ability to demonstrate important cultural values such as active participation in social and economic life, rational choice, independence, and responsibility (Galvin, 2002).

Many stigma conditions also have an implicit moral responsibility that one will make an effort to overcome the stigma. As mentioned above, in Parson's (1951) concept of sick role, people with illness are socially obligated to make an effort to get well quickly. Under this view, smokers should make an effort to quit smoking, overweight people must make an effort to lose weight, and gay and lesbian people should seek therapy to become heterosexual. Under this view, we only have ourselves to blame when we knowingly 
engage in behaviors that endanger our health or social status, highlighting the responsibility dimension of stigma.

Morality and values are closely associated with religion, and the religious domain presents fertile ground for the discussion of stigma. Religious disagreements surrounding issues of morality and appropriate beliefs and behaviors are often seen within the United States between Christianity, Islam, other faiths, secularism, and even sects within the major religions (Gartenstein-Ross, 2005). Nonbelievers often feel so stigmatized that they see themselves as "relegated to a closet that is darker and deeper than that which gays and lesbians find themselves" (Blummer, 2005, p. 4).

Morality is clearly an issue for gay and lesbian identities because of widely held social attitudes of homophobia and heterosexism. For example, the sexuality of gay and lesbian people is portrayed as perverse and depraved, a view prevalent in criminal statutes that equate sodomy with bestiality and crimes against nature (Ball, 2002). It violates cultural "purity" values and is seen as both a tangible and symbolic threat (Stangor \& Crandall, 2000). Homosexuality is highly stigmatized by fundamentalist Christians (Jelen, 1991; Wilkinson \& Roys, 2005). This stigma is based on inaccurate stereotypes about gay lifestyle. In a recent content analysis of conservative Christian literature regarding homosexuality, Herman (1997) found a common depiction of gay male sexuality as being characterized by abnormally high amounts of sexual activity and including frequent atypical behaviors such as sadomasochism.

The differences in attitudes and beliefs between fundamentalist Christians and gay and lesbian people are especially challenging for employers seeking to provide a tolerant and inclusive workplace. These two diversity groups have mutually exclusive beliefs which are impossible to reconcile. This was illustrated in a recent legal confrontation in which a Christian employee refused to sign an employee handbook because he could not agree to abide by the company policy which required him to "respect and value" differences, including sexual orientation (Buonanno v. AT\&T Broadband, D. Colo., No. 02-CV-778, April 1, 2004). The court upheld the employee's claim that the company failed to accommodate his religious beliefs. The court stated, "[H]ad AT\&T gathered more information about Buonanno's concerns before terminating his employment, it may have discovered that the perceived conflict between his beliefs and AT\&T's policy was not an actual conflict at all, or that if a true conflict existed, it was possible to relieve that conflict with a reasonable accommodation." The court awarded the employee approximately $\$ 150,000$ in back pay and emotional distress damages (Clark, 2004).

\section{Performance}

The fourth dimension that varies among invisible diversities is the issue of performance, specifically whether the different identity will affect the individual's job performance. Jones et al. (1984) address this concept as disruptiveness and define this as interference with interaction and communication. In the workplace, communication and performance are the key processes where disruptiveness is salient. Empirical research by McLaughlin et al. (2004) found that performance impact was the only one of several stigma factors that was significantly related to acceptance by coworkers. If an employee's disability decreased their job performance, they were more stigmatized by their coworkers. 
In the cases of illness and disability, performance outcomes can occur when these conditions alter peoples' physical and mental abilities. In contrast, sexual preference and religion should have no influence on an individual's ability to perform job tasks. However stigma can influence group performance because of its impact on social processes. Jackson and Joshi (2001) offer a two-dimensional typology for the content of diversity that distinguishes between readily detectable and underlying attributes on one dimension and taskvs. relationship-oriented attributes on another. This typology raises the important distinction that some differences, such as religious beliefs, ethnic, racial, and sexual identities are not directly task-related. Researchers often assume that task-related attributes are more central than relationship-oriented ones in determining behavior and outcomes. However, relationship-oriented attributes trigger stereotypes that influence cognitive framing, social interaction, communication patterns, and decision making (Jackson \& Joshi, 2001). It is in these interactions that invisible identities end up making a difference. When stereotypes are negative, diversity can cause performance problems for the group because of increased group conflict (Jackson \& Joshi, 2001; Richard et al., 2002). These performance problems can ripple through the organization to cause larger performance problems as well.

\section{IMPLICATIONS FOR EMPLOYERS AND GAY AND LESBIAN EMPLOYEES}

We have discussed the current state of legal protections, and the sociological and cultural process that affect people with invisible social identities in their employment relationships. People with invisible social identities may face social or physical barriers that hinder both their performance and their satisfaction at work. Creating a workplace environment that can accommodate the variations of its employees is both socially responsible and economically sensible. We now propose some recommendations to help organizations and individuals meet the challenges of invisible diversity.

First, organizations should be aware of the special challenges faced by people with invisible social identities. These challenges include the dilemma of disclosure and the stress associated with information management. People with stigmatized differences may experience strained social interactions, isolation, and decreased self-esteem (Crocker \& Major, 1989). Identifying people with invisible social identities is difficult, but fortunately this is not necessary to make the workplace more accommodating. Simply increasing manager's awareness of these issues, and making the issues more discussable, can help de-stigmatize invisible identities and create a more nurturing environment. Supportive managerial actions and policies also demonstrate an open and accommodating culture, a symbol which is valued by all employees. In fact, research has shown that the having supportive direct supervisors is essential for employees to feel comfortable enough to disclose their gay or lesbian identity (Ragins \& Cornwall, 2001a). It is also important to make jobs as flexible as possible, both in terms of required job tasks and scheduling flexibility, so that career advancement is not blocked by unnecessary job requirements (Beatty \& Joffe, in press).

A sense of isolation is a common experience for people with invisible identities (Frable et al., 1998). Our second recommendation is that it is important for people with invisible identities to recognize that despite their individual sense of isolation, there are many other identity groups that experience similar feelings. Recognizing that they are not alone is helpful because even when recognition is not public, knowing of similar 
others can mitigate any sense of isolation and provide a source of emotional support that comes with shared experience. Frable et al. (1998) suggested that people with concealable stigma lacked expert knowledge of their social group and in empirical research found that they showed immediate benefits in improved self esteem from interaction with similar others.

Recognizing the similarities with other invisible social identity groups is also important for large scale social change because these groups are a source for mobilization and social action. Assuming that advocacy movements follow a similar life cycle of development, invisible identity groups can learn from each other's experiences. A comparison with visible minority groups illustrates the elements of social change. Visible minority groups are identified by observable characteristics, differential power, discrimination, and group awareness (Dworkin \& Dworkin, 1999). The women's movement and civil rights movements are both examples of visible minority groups that demanded significant cultural and legal changes in an effort to achieve equal access to important human rights. Both groups have observable characteristics and experienced differential power and discrimination. However, because of longstanding social and cultural norms, the discrimination these groups experienced was taken-for-granted in the larger society, essentially invisible to many in the majority. By increasing their own group awareness, both groups were able to challenge the systematic discrimination they faced. A key strategy for both groups was that they banded together and made themselves highly visible.

People with invisible identities have a more difficult time mobilizing because they lack visibility and group awareness; thus, it is very difficult to identify similar others with whom to join cause (Scotch, 1988). Further, the negative connotations and potential stigma associated with some of the differences also interfere with the formation of group awareness because people are reluctant to publicly claim a potentially damaging identity. Thus our third recommendation addresses the central issue of visibility, which seems to hold the key to social and cultural acceptance. The historical experience of other stigmatized social identity groups suggests that the way to overcome the taken-for-granted social structure is to become visible. Being visible means declaring one's hidden identity, "coming out" to the world.

The connection between visibility and political action is well understood in the gay and lesbian community. The Human Rights Campaign (HRC), the largest gay and lesbian political organization, sponsors a "National Coming Out Day" each October to encourage gays and lesbians to come out. The HRC's position is that being open about homosexuality will change social and cultural attitudes towards homosexuality (Dworkin \& Dworkin, 1999). But cultural change is a long-term proposition with a generalized beneficiary; the short term difficulties are immediate, risky, and highly personal. Given the differing levels of acceptance across the country, it would be naïve to suggest that all gay people should come out. Each person must weigh the advantages and disadvantages of disclosure based on their individual circumstances and personal preferences.

Acknowledging this limitation, when people are willing to come out and be open about being gay or lesbian, they help set the stage for social change. Creed and Scully (2000) discuss the ways that gay and lesbian employees used "identity deployment" in microencounters with coworkers to change others' attitudes. From this we see that social change happens over time, one encounter at a time. 
Although the existing legal protections have been helpful, some areas are not well defined and are awaiting the development that comes with a body of case law. Gay and lesbian employees are still waiting for adequate comprehensive federal legal protection against employment discrimination. Advocates should continue to press for adoption of ENDA and, given ENDA's limited scope, the development of more extensive laws as well. Antidiscrimination laws send a signal to employers that discrimination in employment practices is a risky behavior, and the benefit is that these laws will deter some discrimination from ever taking place. However, the laws discussed here create groups of individuals in "protected classes." Ironically, the laws that protect people with invisible identities also create and reinforce stigma by naming and categorizing groups (Gordon \& Rosenblum, 2001). It is easy for defined social groups to become fragmented special interests, with agendas based on the defining interest. Recognizing similarities counteracts this fragmentation and allows for sharing of ideas across special interest groups.

People with invisible differences gain membership in a protected class by disclosing their difference, requiring the individual to out themselves to the legal system. They are then subject to an inhospitable social and cultural environment. Thus while improved legal protections are necessary, establishing a more hospitable social and cultural environment is a catalyst and most likely a necessary precondition that sets the stage for improved legal protections. After all, discrimination and stigma are sociological processes that cannot be legislated away. Underlying cultural attitudes which are at the root of prejudice must shift as well. Because for most people legal action is seen as a last resort, much work must go on below the threshold of legal action to manage invisible identities. Increasing awareness of these groups, including their challenges and similarities, is an important first step.

\section{REFERENCES}

Ball, C. (2002). That we are human, we have rights. Gay and Lesbian Review Worldwide, 9(6), 31.

Beatty, J. E. (2004). Chronic illness as invisible diversity: Disclosing and coping with illness in the workplace. Unpublished Dissertation, Boston College, Boston, MA.

Beatty, J. E., \& Kirby, S. (2004). Feeling misunderstood: The emotional experiences of people with invisible identities. Paper presented at the Academy of Management Annual Conference, New Orleans, LA.

Beatty, J. E., \& Joffe, R. (in press). An overlooked dimension of diversity: The career effects of chronic illness. Organizational Dynamics.

Bell, M. P., McLaughlin, M. E., \& Sequeira, J. M. (2004). Age, disability, and obesity: Similarities, differences, and common threads. In Stockdale, M. S., \& Crosby, F. J. (Eds.), The psychology and Management of Workplace Diversity, 191-205. Malden, MA: Blackwell.

Blummer, R. (2005). I am an atheist. . .so what? Freethought Today, March, pp. 4-5.

Bobys, R. S., \& Laner, M. R. (1979). On the stability of stigmatization: The case of ex-homosexual males. Archives of Sexual Behavior, 8(3), 247-261.

Cahill, S. (2005). The Glass Nearly Half Full. Washington, DC: National Gay and Lesbian Task Force Policy Institute.

Cass, V. C. (1984). Homosexual identity formation: Testing a theoretical model. Journal of Sex Research, 20, $143-167$.

Charmaz, K. (1987). Struggling for self: Identity levels of the chronically ill. In Roth, J. A., \& Conrad, P. (Eds.), Research in the Sociology of Health Care. Greenwich, CT: JAI Press.

Charmaz, K. (1991). Good Days, Bad Days: The Self in Chronic Illness and Time. New Brunswick, NJ: Rutgers University Press.

Clair, J. A., Beatty, J. E., \& MacLean, T. L. (2005). Out of sight but not out of mind: Managing invisible social identities in the workplace. Academy of Management Review, 30(1), 78-95.

Clark, M. (2004). Religion vs. sexual orientation. HR Magazine, 49(8), 54-59.

Colella, A. (2001). Coworker distributive fairness judgments of the workplace accommodation of employees with disabilities. Academy of Management Review, 26, 100-116. 
Corrigan, P. (Ed.). (2004). On the Stigma of Mental Illness: Practical Strategies for Research and Social Change. Washington, DC: American Psychological Association.

Creed, W. E. D., \& Scully, M. A. (2000). Songs of ourselves: Employees' deployment of social identity in workplace encounters. Journal of Management Inquiry, 9, 391-413.

Crocker, J., \& Major, B. (1989). Social stigma and self-esteem: The self-protective properties of stigma. Psychological Review, 96, 608-630.

Crocker, J., Major, B., \& Steele, C. (1998). Social stigma. In Gilbert, D. T., Fiske, S. T., \& Lindzey, G. (Eds.), Handbook of Social Psychology. 4th ed.: 504-553. New York: McGraw Hill.

Croteau, J. M. (1996). Research on the work experience of lesbian, gay, and bisexual people: An integrative review of methodology and findings. Journal of Vocational Behavior, 48, 195-209.

Dawkins, R. (2003). A Devil's Chaplain: Reflections on Hope, Lies, Science, and Love. Boston: Houghton Mifflin.

Day, N. E., \& Schoenrade, P. (1997). Staying in the closet versus coming out: Relationships between communication about sexual orientation and work attitudes. Personnel Psychology, 50(Spring), 147-164.

Delbecq, A. (2002). Hidden holy people. Paper presented at the Academy of Management Annual Conference, Denver, CO.

Driscoll, J. M., Kelley, F. A., \& Fassinger, R. E. (1996). Lesbian identity and disclosure in the workplace: Relation to occupational stress and satisfaction. Journal of Vocational Behavior, 48, 229-242.

Dworkin, A. G., \& Dworkin, R. J. (1999). The Minority Report: An Introduction to Racial, Ethnic, and Gender Relations, 3rd ed. Orlando, FL: Harcourt Brace.

Falk, G. (2001). Stigma: How We Treat Outsiders. Amherst, NY: Prometheus Books.

Farina, A., Holland, C. H., \& Ring, K. (1966). The role of stigma and set in interpersonal interaction. Journal of Abnormal Psychology, 71, 421-428.

Frable, D. E. S., Platt, L., \& Hoey, S. (1998). Concealable stigmas and positive self-perceptions: Feeling better around similar others. Journal of Personality and Social Psychology, 74(4), 909-922.

Freeman, H. E. (1961). Attitudes toward mental illness among relatives of former patients. American Sociological Review, 26, 56-66.

Galvin, R. (2002). Disturbing notions of chronic illness and individual responsibility: Towards a genealogy of morals. Health, 6(2), 107-137.

Garnets, L., \& Kimmel, D. (1991). Lesbian and gay male dimensions in the psychological study of human diversity. In Goodchilds, J. D. (Ed.), Psychological Perspectives on Human Diversity in America. Washington, DC: American Psychological Association.

Gartenstein-Ross, D. (2005). No other Gods before me: Spheres of influence in the relationship between Christianity and Islam. Denver Journal of International Law and Policy, 33, 223.

Goffman, E. (1963). Stigma: Notes on the Management of Spoiled Identity. Englewood Cliffs, NJ: Prentice Hall.

Gordon, B. O., \& Rosenblum, K. E. (2001). Bringing disability into the sociological frame: A comparison of disability with race, sex, and sexual orientation statuses. Disability and Society, 16(1), 5-19.

Harrison, D. A., Price, K. H., \& Bell, M. P. (1998). Beyond organizational demography: Time and the effects of surface-versus deep-level diversity on work groups. Academy of Management Journal, 41(1), 96-107.

Herek, G. M. (1996). Why tell if you are not asked?: Self-disclosure, intergroup contact, and heterosexuals' attitudes toward lesbians and gay men. In Herek, G. M., Jobe, J. B., \& Carney, R. M. (Eds.), Out in Force: Sexual Orientation and the Military, 197-225. Chicago: University of Chicago Press.

Herman, D. (1997). The Antigay Agenda: Orthodox Vision and the Christian Right. Chicago: University of Chicago Press.

Herrschaft, D. (2004). State of the Workplace for Lesbian, Gay, Bisexual, and Transgender Americans. Washington, DC: Human Rights Campaign Foundation.

Jackson, S. E., \& Joshi, A. (2001). Research on domestic and international diversity management in organizations: A merger that works? In Anderson, N., Ones, D. S., Sinangil, H. K., \& Viswesvaran, C. (Eds.), Handbook of Industrial, Work, and Organizational Psychology, Vol. 2, 206-231. London: Sage.

Jelen, T. G. (1991). The Political Mobilization of Religious Beliefs. New York: Praeger.

Jones, E. E., Farina, A., Hastorf, A. H., Markus, H., Miller, D. T., \& Scott, R. A. (1984). Social Stigma: The Psychology of Marked Relationships. New York: W. H. Freeman.

Kramer, B. (1999). Reconciling religious rights and responsibilities. Loyola University Chicago Law Journal, 30, 439.

Levine, J. M., \& McBurney, D. H. (1977). Causes and consequences of effluvia: Body odor awareness and controllability as determinants of interpersonal evaluation. Personality and Social Psychology Bulletin, 3, $442-445$.

Levine, M. P. (1979). Employment discrimination against gay men. International Review of Modern Sociology, 9, 151-163.

Levine, M. P., \& Leonard, R. (1984). Discrimination against lesbians in the work force. Signs: Journal of Women in Culture and Society, 9, 700-710.

Liachowitz, C. H. (1988). Disability as a Social Construct. Philadelphia, PA: University of Pennsylvania Press.

Link, B. G., \& Phelan, J. C. (2001). Conceptualizing stigma. Annual Review of Sociology, 27, 363-385. 
Matthews, C. K., \& Harrington, N. G. (2000). Invisible disability. In Braithwaite, D. O., \& Thompson, T. L. (Eds.), Handbook of Communication and People with Disabilities: 405-421. Mahwah, NJ: Erlbaum.

McGuire, W. J. (1984). Search for the self: Going beyond self-esteem and the reactive self. In Zucker, R. A., Aronoff, J., \& Rabin, A. I. (Eds.), Personality and the Prediction of Behavior, 73-120. New York: Academic Press.

McLaughlin, M. E., Bell, M. P., \& Stringer, D. Y. (2004). Stigma and acceptance of persons with disabilities. Group and Organization Management, 29(3), 302-333.

Miller, A. S. (1996). The influence of religious affiliation on the clustering of social attitudes. Review of Religious Research, 37(3), 219-232.

Moorhead, C. (1999). Queering identities: The roles of integrity and belonging in becoming ourselves. Journal of Gay, Lesbian, and Bisexual Identity, 4(4), 327-343.

Page, D. D. (2005). Veganism and sincerely held "religious" beliefs: No protection without definition. Journal of Employment Law, 7, 363.

Parsons, T. (1951). The Social System. Glencoe, IL: Free Press.

Pfeffer, D. (2001). The conceptualization of disability. Research in Social Science and Disability, 2, $29-52$.

Ragins, B. R., \& Cornwall, J. M. (2001a). Walking the line: Fear and disclosure of sexual orientation in the workplace. Paper presented at the Academy of Management Annual Meeting, Washington, DC.

Ragins, B. R., \& Cornwall, J. M. (2001b). Pink triangles: Antecedents and consequences of perceived workplace discrimination against gay and lesbian employees. Journal of Applied Psychology, 86(6), 12441261.

Repa, B. (2005). Your Rights in the Workplace, 7th ed., Berkeley: Nolo Press.

Richard, O. C., Kochan, T. A., \& McMillan-Capehart, A. (2002). The impact of visible diversity on organizational effectiveness: Disclosing the contents in Pandora's black box. Journal of Business and Management, 8(3), $265-291$.

Rudin, J. P., \& Harshman, E. (2004). Keeping the faith but losing in court: Legal implications of proselytizing in the workplace. Employee Rights and Responsibilities Journal, 16(2), 105-209.

Schuchman, A. D. (1998). The holy and the handicapped: An examination of the different applications of the reasonable-accommodations clauses in Title VII and the ADA. Indiana Law Journal, 73, 745.

Schulte, A. (2002). Consensus versus disagreement in disease-related stigma: A comparison of reactions to AIDS and cancer patients. Sociological Perspectives, 45(1), 81-104.

Schwartz, C. G. (1957). Perspectives on deviance: Wive's definitions of their husband's mental illness. Psychiatry, 20, 257-291.

Scotch, R. K. (1988). Disability as the basis for a social movement: Advocacy and the politics of definition. Journal of Social Issues, 44(1), 159-172.

Sheffield, J. W. (2005). Navigating current trends under the ADA. Employee Relations Law Journal, 31(1), 3-20.

Smart, L., \& Wegner, D. M. (2000). The hidden costs of hidden stigma. In Heatherton, T. F., Kleck, R. E., Hebl, M., \& Hull, J. (Eds.), The Social Psychology of Stigma, 220-241. New York, Guilford Press.

Smedley, A. (1999). Race in North America: Origin and Evolution of a Worldview. Boulder, CO: Westview Press.

Stangor, C., \& Crandall, C. S. (2000). Threat and the social construction of stigma. In Heatherton, T. F., Kleck, R. E., Hebl, M. R., \& Hull, J. G. (Eds.), The Social Psychology of Stigma. New York, Guilford Press.

Stark, R., \& Bainbridge, W. S. (1987). A Theory of Religion. New York: Lang.

Stone, D. L., \& Colella, A. (1996). A model of factors affecting the treatment of disabled individuals in organizations. Academy of Management Review, 21(2), 352-401.

Tajfel, H., \& Turner, J. C. (1985). The social identity theory of intergroup behavior. In Worchel, S., \& Austin, W. G. (Eds.), Psychology of Intergroup Relations, 7-24. Chicago: Nelson-Hall.

Taylor, H. (2002). Workplace Discrimination Against, and Jokes About, African Americans, Gays, Jews, Muslims, and Others. New York: Harris Interactive.

U.S. Equal Employment Opportunity Commission (2005a) Disability discrimination. Available at http:// www.eeoc.gov/types/ada.html.

U.S. Equal Employment Opportunity Commission (2005b) Religious Discrimination. Available at http:// www.eeoc.gov/types/religion.html.

Vann, D. H. (1976). Personal Responsibility, Authoritarianism and Treatment of the Obese, Unpublished Dissertation, New York University.

Wahl, O. F. (1999). Telling is Risky Business: The Experience of Mental Illness Stigma. Piscataway, NJ: Rutgers University Press.

Ware, N. C. (1999). Toward a model of social course in chronic illness: The example of chronic fatigue syndrome. Culture, Medicine, and Psychiatry, 23, 303-331.

Weiner, B., Perry, R. P., \& Magnusson, J. (1988). An attributional analysis of reactions to stigmas. Journal of Personality and Social Psychology, 55(5), 738-748.

Weithoff, C. (2003). In and out of the broom closet: When do Wiccans choose to disclose their religious identity at work? Paper presented at the Academy of Management Annual Conference, Seattle, WA.

West, P. (2004). I'm no atheist, I'm a rationalist. Newstatesman, November, p. 13. 


\section{Beatty and Kirby}

Wilkinson, W. W., \& Roys, A. C. (2005). The components of sexual orientation, religiosity, and heterosexuals' impressions of gay men and lesbians. Journal of Social Psychology, 145(1), 65-83.

Woods, J. D. (1994). The Corporate Closet. New York: Free Press.

Woods, S. E., \& Harbeck, K. M. (1991). Living in two worlds: The identity management strategies used by lesbian physical educators. In Harbeck, K. (Ed.), Coming Out of the Classroom Closet: Gay and Lesbian Students, Teachers, and Curricula, 141-166. New York: Harrington Park Press. 